\title{
Evolution and tinkering: what do a protein kinase, a transcriptional regulator and chromosome segregation/cell division proteins have in common?
}

\author{
Abderahmane Derouiche $^{1} \cdot$ Lei Shi $^{1} \cdot$ Aida Kalantari $^{1} \cdot$ Ivan Mijakovic $^{1}$
}

Received: 6 August 2015 / Revised: 8 August 2015 / Accepted: 10 August 2015 / Published online: 19 August 2015

(C) Springer-Verlag Berlin Heidelberg 2015

\begin{abstract}
In this study, we focus on functional interactions among multi-domain proteins which share a common evolutionary origin. The examples we develop are four Bacillus subtilis proteins, which all possess an ATPbinding Walker motif: the bacterial tyrosine kinase (BYkinase) PtkA, the chromosome segregation protein Soj (ParA), the cell division protein MinD and a transcription regulator SalA. These proteins have arisen via duplication of the ancestral ATP-binding domain, which has undergone fusions with other functional domains in the process of divergent evolution. We point out that these four proteins, despite having very different physiological roles, engage in an unusually high number of binary functional interactions. Namely, MinD attracts Soj and PtkA to the cell pole, and in addition, activates the kinase function of PtkA. SalA also activates the kinase function of PtkA, and it gets phosphorylated by PtkA as well. The consequence of this phosphorylation is the activation of SalA as a transcriptional repressor. We hypothesize that these functional interactions remain preserved during divergent evolution and represent a constraint on the process of evolutionary "tinkering", brought about by fusions of different functional domains.
\end{abstract}

Keywords Protein phosphorylation - Cell division . DNA-binding domain - Transcriptional regulation . ATPase $\cdot$ Divergent evolution

Communicated by M. Kupiec.

Ivan Mijakovic

ivan.mijakovic@chalmers.se

Systems and Synthetic Biology, Department of Biology and Biological Engineering, Chalmers University of Technology, Göteborg, Sweden

\section{PtkA, SalA, MinD and Soj contain the same ATP-binding domain}

The notion of tinkering in evolution was introduced by Jacob (1977). In a nutshell, the idea is that evolution proceeds by the principle of "bricolage", using the available components to put together new molecular "devices". One of the molecular mechanisms underlying this process is duplication of ancestral proteins domains, which fuse with other protein domains, and these combinations lead to new biological functions (Van Damme et al. 2007). A noteworthy aspect of this process, which acts as a constraint for divergent evolution and "tinkering", is the preservation of the interfaces for protein-protein interactions (Heringa and Taylor 1997). Here we will focus on four Bacillus subtilis proteins with very different present-day functions, which have evolved from the same ancestral ATPase domain (Walker et al. 1982). Their common origin from the ancestral Walker-type ATPase has been suggested by Grangeasse et al. (2012), based on extensive sequence homology.

The first protein we will focus on is the BY-kinase PtkA. It employs its ATPase domain as a catalytic site for proteintyrosine kinase activity (Mijakovic et al. 2003). PtkA phosphorylates and regulates the activity of several protein substrates in B. subtilis (Mijakovic et al. 2006; Jers et al. 2010; Derouiche et al. 2013, 2015). The second protein is Soj (ParA). Soj acts at the replication origin, where it controls the activity of the DNA replication initiator protein DnaA (Murray and Errington 2008; Scholefield et al. 2012). Interestingly, Soj requires ATP-binding by its ATPase domain to dimerize and become capable of binding the DNA at the replication origin (Scholefield et al. 2011). The third protein, MinD, localizes at the cell poles, and via activation of MinC, ensures the selection of the mid-cell division site 


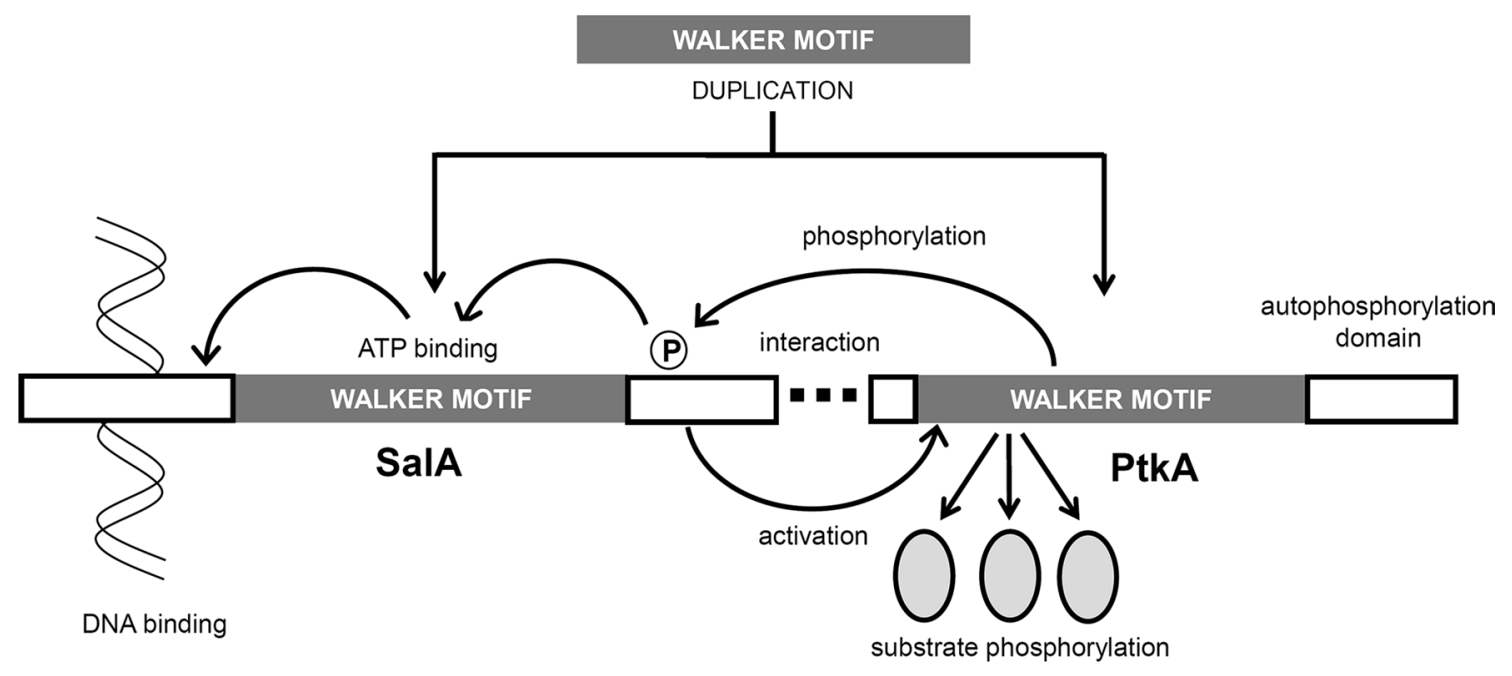

Fig. 1 Functional interaction between SalA and PtkA. Both proteins contain the same Walker motif domain (grey box), derived from domain duplication. The interaction between the two proteins leads to phosphorylation of SalA, and activation of its function as a tran-

(Marston and Errington 1999). Finally, the fourth protein we will focus on, SalA, was characterized more recently. SalA has been classified as a member of the Mrp protein family (Dardel et al. 1991). Due to its similarity to Soj, it can still be found erroneously classified as a ParA protein in several online databases. Ogura et al. (2004) have described B. subtilis SalA as an activator of the exoprotease AprE. They described the activation of aprE expression by SalA as a two-step process: SalA somehow the transcription of $s c o C$, which encodes a repressor of aprE. However, Ogura et al. (2004) detected no DNA-binding domain in $\mathrm{SalA}$, and concluded that the repression of $s c o C$ is indirect. Recently, Derouiche et al. (2015) identified a DNA-binding domain at the C-terminus of SalA, and demonstrated that SalA represses $s c o C$ via direct binding to its promoter sequence ( -35 to -6 with respect to the transcription start site). Similarly to Soj, SalA DNA-binding domain is also activated by ATP-binding to its ATPase domain (Derouiche et al. 2015).

\section{Functional interactions preserved through domain duplication and divergent evolution}

Based on recent evidence, we would like to argue that the divergent evolution of these four proteins, harboring the same ATP-binding domain, has been constrained by functional interactions established among them. Resolved structures of MinD proteins and BY-kinases support the notion that the ATP-binding domains of these proteins have a very similar fold (Olivares-Illana et al. 2008; Wu et al. 2011). Since all these proteins form oligomers, the scriptional repressor of $\operatorname{scoC}$. The interaction also activates the kinase function of PtkA, which, in the activated form, phosphorylates its other protein substrates

interactions among them can be easily modeled as "oligomerization" events. Functional interaction of MinD and Soj has been reported by Autret and Errington (2003). They described a mutant of Soj, incapable of hydrolysing ATP, which interacts specifically with the cell pole; in MinD-dependent manner (the interaction was not dependent on MinC). Recently, a direct physical interaction between MinD and PtkA was reported by Shi et al. (2014). MinD was found to attract PtkA to the cell pole, and to enhance its kinase activity. One of the possible consequences of this interaction is PtkA-dependent phosphorylation of the cell division protein DivIVA (Shi et al. 2014). Arguably the most remarkable interaction is that between SalA and PtkA (Fig. 1). SalA contains in its C-terminus a domain (residues 294-352) which bears structural resemblance to the canonical activator of PtkA, TkmA (Mijakovic et al. 2003). This very same SalA domain was identified as the minimal domain required for interaction with PtkA (Derouiche et al. 2015). The consequences of this interaction are two-fold. The interaction leads to PtkA-dependent phosphorylation of SalA residue Y327. This enhances the SalA ATP-binding and hydrolysis, and ultimately leads to stronger binding to the SalA DNA target site. The physiological consequence is the repression of $s c o C$ and activation of aprE expression (Derouiche et al. 2015). On the other hand, SalA activates the kinase function of PtkA. Namely, it enables the kinase to phosphorylate a number of its substrates, and it does so by competing for the same binding site with the other PtkA activator, TkmA (Derouiche and Mijakovic, unpublished results). This two-way activation thus represents a mutual regulatory loop. 


\section{An exception or a rule?}

These examples of well documented binary functional interactions among four B. subtilis proteins evolved from the common ancestral ATPase domain raise a number of questions. Given the known cell cycle phenotype of the $p t k A$ mutant (Petranovic et al. 2007), it is tempting to ask whether Soj and PtkA might also engage in some sort of functional interaction. Thinking more globally, should evolutionary analyses and phylogenomics studies be systematically coupled to interactomics studies, when one seeks to define the functional interaction networks in systems biology? To the best of our knowledge, this question has not been addressed in the literature. It has been established that protein-protein interactions tend to be preserved in the process of domain duplication (Evlampiev and Isamberth 2007). However, such studies have mostly examined members of protein families which have preserved the same function, such as transcription factors (Veron et al. 2007) or SH2-domain proteins (Liu and Nash 2012). Interactions among proteins of the same origin but different presentday functions have not been examined systematically. The closest approximation to our example from $B$. subtilis is the study by Osadnik et al. (2015), where the authors describe two Escherichia coli proteins of the AAA+ family, a transcription factor PspF and a protein unfoldase $\mathrm{ClpB}$, which have both retained a conserved coiled-coil domain. This is a protein-protein interaction domain which allows these AAA+ proteins to be activated by the same mechanism, despite their different functions. Our hypothesis that proteins which share a common evolutionary origin may have a higher propensity to functionally interact will have to be tested by systematic examination of interactomics datasets.

Acknowledgments This work was supported by the grant from the Chalmers University of Technology to IM.

\section{References}

Autret S, Errington J (2003) A role for division-site-selection protein MinD in regulation of internucleoid jumping of Soj (ParA) protein in Bacillus subtilis. Mol Microbiol 47:159-169

Dardel F, Panvert M, Blanquet S, Fayat G (1991) Locations of the metG and mrp genes on the physical map of Escherichia coli. J Bacteriol 173:3273

Derouiche A, Bidnenko V, Grenha R, Pigonneau N, Ventroux M, Franz-Wachtel M, Nessler S, Noirot-Gros MF, Mijakovic I (2013) Interaction of bacterial fatty-acid-displaced regulators with DNA is interrupted by tyrosine phosphorylation in the helix-turn-helix domain. Nucleic Acids Res 41:9371-9381

Derouiche A, Shi L, Bidnenko V, Ventroux M, Pigonneau N, FranzWachtel M, Kalantari A, Nessler S, Noirot-Gros MF, Mijakovic I (2015) Bacillus subtilis SalA is a phosphorylation-dependent transcription regulator that represses scoC and activates the production of the exoprotease AprE. Mol Microbiol. doi:10.1111/ mmi.13098
Evlampiev K, Isamberth H (2007) Modeling protein network evolution under genome duplication and domain shuffling. BMC Syst Biol 1:49

Grangeasse C, Nessler S, Mijakovic I (2012) Bacterial tyrosine kinases: evolution, biological function and structural insights. Philos Trans R Soc Lond B Biol Sci 367:2640-2655

Heringa J, Taylor WR (1997) Three-dimensional domain duplication, swapping and stealing. Curr Opin Struct Biol 7:416-421

Jacob F (1977) Evolution and tinkering. Science 196:1161-1166

Jers C, Pedersen MM, Paspaliari DK, Schütz W, Johnsson C, Soufi B, Macek B, Jensen PR, Mijakovic I (2010) Bacillus subtilis BYkinase PtkA controls enzyme activity and localization of its protein substrates. Mol Microbiol 77:287-299

Liu BA, Nash PD (2012) Evolution of SH2 domains and phosphotyrosine signalling networks. Philos Trans R Soc Lond B Biol Sci 367:2556-2573

Marston AL, Errington J (1999) Selection of the midcell division site in Bacillus subtilis through MinD-dependent polar localization and activation of MinC. Mol Microbiol 33:84-96

Mijakovic I, Poncet S, Boël G, Mazé A, Gillet S, Jamet E, Decottignies P, Grangeasse C, Doublet P, Le Maréchal P, Deutscher J (2003) Transmembrane modulator-dependent bacterial tyrosine kinase activates UDP-glucose dehydrogenases. EMBO J 22:4709-4718

Mijakovic I, Petranovic D, Macek B, Cepo T, Mann M, Davies JD, Jensen PR, Vujaklija D (2006) Bacterial single-stranded DNAbinding proteins are phosphorylated on tyrosine. Nucleic Acids Res 34:1588-1596

Murray H, Errington J (2008) Dynamic control of the DNA replication initiation protein DnaA by Soj/ParA. Cell 135:74-84

Ogura M, Matsuzawa A, Yoshikawa H, Tanaka T (2004) Bacillus subtilis SalA (YbaL) negatively regulates expression of scoC, which encodes the repressor for the alkaline exoprotease gene, aprE. J Bacteriol 186:3056-3064

Olivares-Illana V, Meyer P, Bechet E, Gueguen-Chaignon V, Soulat D, Lazereg-Riquier S, Mijakovic I, Deutscher J, Cozzone AJ, Laprévote O, Morera S, Grangeasse C, Nessler S (2008) Structural basis for the regulation mechanism of the tyrosine kinase CapB from Staphylococcus aureus. PLoS Biol 6:e143

Osadnik H, Schöpfel M, Heidrich E, Mehner D, Lilie H, Parthier C, Risselada HJ, Grubmüller H, Stubbs MT, Brüser T (2015) The PspF-binding domain PspA1-144 and the PspA.F complex New insights into the coiled-coil dependent regulation of AAA+ proteins. Mol Microbiol. doi:10.1111/mmi.13154

Petranovic D, Michelsen O, Zahradka K, Silva C, Petranovic M, Jensen PR, Mijakovic I (2007) Bacillus subtilis strain deficient for the protein-tyrosine kinase PtkA exhibits impaired DNA replication. Mol Microbiol 63:1797-1805

Scholefield G, Whiting R, Errington J, Murray H (2011) Spo0 J regulates the oligomeric state of Soj to trigger its switch from an activator to an inhibitor of DNA replication initiation. Mol Microbiol 79:1089-1100

Scholefield G, Errington J, Murray H (2012) Soj/ParA stalls DNA replication by inhibiting helix formation of the initiator protein DnaA. EMBO J 31:1542-1555

Shi L, Pigeonneau N, Ventroux M, Derouiche A, Bidnenko V, Mijakovic I, Noirot-Gros MF (2014) Protein-tyrosine phosphorylation interaction network in Bacillus subtilis reveals new substrates, kinase activators and kinase cross-talk. Front Microbiol 5:538

Van Damme EJ, Nakamura-Tsuruta S, Smith DF, Ongenaert M, Winter HC, Rougé P, Goldstein IJ, Mo H, Kominami J, Culerrier R, Barre A, Hirabayashi J, Peumans WJ (2007) Phylogenetic and specificity studies of two-domain GNA-related lectins: generation of multispecificity through domain duplication and divergent evolution. Biochem J 404:51-61 
Veron AS, Kaufmann K, Bornberg-Bauer E (2007) Evidence of interaction network evolution by whole-genome duplications: a case study in MADS-box proteins. Mol Biol Evol 24:670-680

Walker JE, Saraste M, Runswick MJ, Gay NJ (1982) Distantly related sequences in the alpha- and beta-subunits of ATP synthase, myosin, kinases and other ATP-requiring enzymes and a common nucleotide binding fold. EMBO J 1:945-951
Wu W, Park KT, Holyoak T, Lutkenhaus J (2011) Determination of the structure of the MinD-ATP complex reveals the orientation of MinD on the membrane and the relative location of the binding sites for MinE and MinC. Mol Microbiol 79:1515-1528 